\title{
Commentaries
}

\section{Gene therapy for the eye}

Gene therapy implies the delivery of genes to somatic tissues for therapeutic purposes. ${ }^{12}$ The eye is an attractive target for gene therapy because of its accessibility and its immune privilege. However, over the past few years gene therapy has taken some hard knocks, both from a disillusioned stock market and, more tellingly, from a distinguished peer review committee. ${ }^{3}$ The latter concluded that more time should be spent on understanding and improving potential strategies at a basic science level and less on publishing hasty, poorly controlled clinical experiments. The premature scramble towards clinical studies prompted the taunt 'less hype, more biology' in a Science article. ${ }^{5}$ The question arises as to whether there are lessons here for the expanding group of researchers working towards ocular gene therapy.

One of the most stringent tests of a gene therapy would be to replace the function of a defective ocular gene, since this requires the introduction and long term expression of a functional copy into many, if not a majority of, target cells. In the case of the retina, for example, specific genetic defects have been found in 20 of the 87 mapped genes causing genetic eye disorder. ${ }^{6}$ Most of these disorders result from single gene defects which are both highly disabling and potentially correctable. As an alternative, transferred genes expressing growth factors may be therapeutic in some of the degenerative disorders. ${ }^{7}$ These aspects of gene therapy have therefore attracted a growing body of researchers bent on revolutionising their treatment. ${ }^{8-14}$

As long term gene expression is the goal, success depends on (i) efficient uptake into the target cells; (ii) avoidance of endocytosis and lysosomal degradation; (iii) import into the nucleus; (iv) stable retention in the nucleus, either as a circular episome (for example, adenovirus) or by integration into the host genome; (v) target cell specific expression of the therapeutic gene, driven by the natural promoter and enhancer elements; (vi) appropriate translation and subcellular localisation of the gene product (Fig 1). The most difficult steps are probably (iii), (iv), and (v)-import of the gene into the nucleus and achieving a stable and correct level of expression. These are major hurdles since they are often poorly understood and difficult to evaluate. What are the available options for retinal gene therapy?

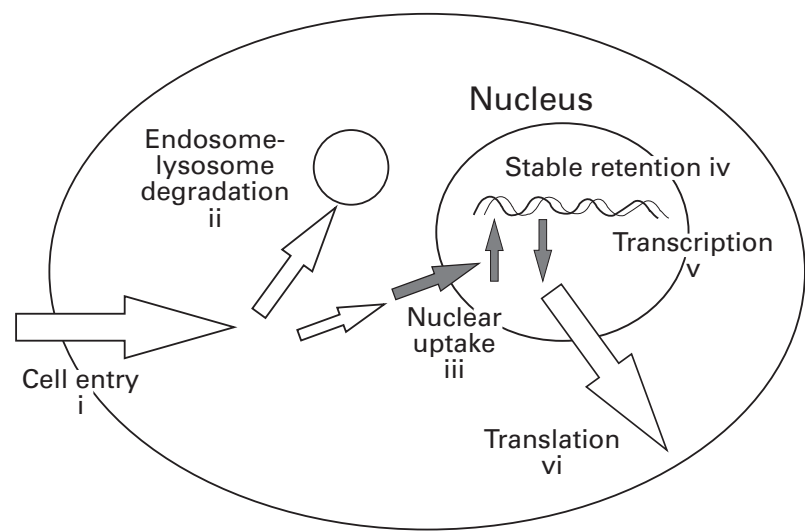

Figure 1 Schematic diagram of the steps involved in cellular uptake and expression of a therapeutic gene. The filled arrows indicate the most difficult steps in achieving effective expression. See text for description.
There are several possible sites for introducing genes into the retina. Intravitreal injection is a relatively safe and easy method of approach but potential complications such as vitreous haemorrhage, retinal detachment, and endophthalmitis cannot be ignored. However, studies using animal models have found that while this is an effective means of transducing ganglion cells, it is much less so for the outer retinal layers. ${ }^{813}$ Our present understanding suggests that most severe human retinal degenerations are primarily disorders of photoreceptors, even though retinal pigment epithelium (RPE) cells may be the initial focus of disease. Subretinal injection, which produces a local and often transient detachment of the retina, has so far been the most favoured means of accessing the photoreceptor layer. ${ }^{8} 9^{12-14}$ This reinforces the idea that very long term expression is necessary to avoid repeated entry. Other possible strategies ${ }^{15}$ include scleral or choroidal gene implants or episcleral injections, with or without iontophoresis to drive the vector into the retina; propulsion of DNA coated gold particles into the retina with a pressurised gene gun; intravenous or intracarotid injection of the transducing agent with the aim of achieving uptake by RPE-all offering radically different approaches. None of these can be completely discounted, bearing in mind the scepticism that greeted vaccination using naked DNA. ${ }^{16} \mathrm{New}$ ideas are always threatening.

In principle, there are several different approaches to obtaining therapeutic expression of introduced genes in the eye, only some of which have been used. These can be broken down into ex vivo and in vivo approaches:

(A) in vivo injection of viral derived vector expressing a therapeutic gene

(B) in vivo injection of genes carried by non-viral agents, such as liposomes or vectors designed for receptor mediated endocytosis

(C) ocular transplantation of ex vivo modified cells.

\section{In vivo injection of viral derived vectors}

The goal is to achieve efficient entry, nuclear uptake, and stable expression in photoreceptors. The native viral DNA is stripped of as many genes as possible to reduce possible toxicity and above all to 'cripple' it by removal of those genes required for replication. Signals required for efficient packaging into the viral coat and for integration or nuclear circularisation (for example, terminal repeats) are retained. Proteins for packaging the DNA into a viral coat are generally supplied by growing the vector in a packaging cell line which supplies them 'in trans' (that is, coded by another chromosome or genome). The choice of currently fashionable viral derived vectors for gene delivery is determined more by availability than suitability. Those currently used include adenovirus, adeno associated virus, and herpes simplex type 1 (HSV1) based vectors. Retroviral vectors can be used to transduce dividing cells such as ocular tumours but are not at present useful for non-dividing, differentiated cells such as photoreceptors (although see below). The advantages and disadvantages of the available vectors have been discussed elsewhere. ${ }^{217}$ What then has been achieved by applying viral derived vectors to the retina?

Transfer of a readily detectable 'reporter gene' (lac $Z, \beta$ galactosidase) to retinal cells and expression lasting 6-13 
weeks has been described following subretinal injection of adenoviral (AV) vectors in mice. ${ }^{89}$ The RPE was efficiently transduced at viral titres of more than $10^{7}$ plaque forming units (pfu). Almost all RPE cells were transduced within the area of subretinal injection but only a small percentage of photoreceptors, except in immature (5-7 day old) or degenerating retinas. ${ }^{89}$ Extraocular tissues were not transduced and retinal toxicity appeared to be low. Transgene expression declined with time because of factors such as low grade immune reaction, switch off, or loss of the episomal transgene. Intravitreal injection was not effective in staining the outer retina or RPE even at titres as high as $10^{9}$ pfu. Similar results have been obtained using adeno associated virus (AAV) based vectors but with more efficient transduction of photoreceptors ${ }^{11-13}$; however, this may result from the presence of contaminating wild type AV. ${ }^{18} 19$ In each case no more than $1 \%$ of photoreceptors were successfully transduced and expression was not stable. However, Bennett and coworkers ${ }^{14}$ using AV vectors expressing the rod cGMP phosphodiesterase gene did succeed in delaying the photoreceptor degeneration in homozygous $r d$ mutant mice for several weeks.

\section{In vivo injection of non-viral agents}

A number of non-viral methods for introducing genes into the retina have yet to be tried, including receptor mediated endocytosis. For example, Hart and coworkers ${ }^{20}$ have described an integrin binding peptide coupled to a polylysine chain which binds vector DNA, facilitating gene uptake into cultured cells. The use of cationic liposomes to target photoreceptors gave unpromising results initially ${ }^{13}$ although this method is notoriously sensitive to the particular liposome used and no systematic study using different liposome preparations has been reported. These approaches circumvent some of the safety concerns raised by viral vectors and the risk of an immune response to the introduced vector proteins is greatly diminished. In addition, liposomes have been reported to facilitate transduction of retroviruses into cells and so may at the least provide a useful adjunct to therapy. ${ }^{21}$

The most promising application of non-viral agents to the retina used a mixture of liposome and expressing plasmid complexed with HMG1 chromosomal proteins, which was then coated with the envelope of Sendai virus (haemagglutinating virus of Japan, HVJ) to promote fusion with the cell membrane. ${ }^{22}$ The HMG1 proteins contain a nuclear localisation signal to facilitate nuclear uptake and may also protect the DNA from degradation. Intravitreal and subretinal injection of a lac $Z$ 'reporter gene' in mice and rats resulted initially in strong blue staining of the photoreceptors, indicating expression, with expression persisting for up to 30 days after injection. Staining of other neurons and glial cells was also seen but this was much less evident in RPE. No evidence of an immune response was seen. As a result of HVJ induced membrane fusion and cytoplasmic entry, the encapsulated plasmid is thought to bypass endocytosis and lysosomal degradation. Nuclear entry was enhanced by the presence of HMG1 proteins, increasing expression up to 10 -fold. However, expression appeared more transient than with $\mathrm{AV}$ vectors since by 30 days after injection there was only weak or no blue staining. ${ }^{22}$

\section{Ocular transplantation of ex vivo modified cells}

The problems of both efficiently and stably transducing photoreceptors suggest an alternative ex vivo approach which currently shows promise in the treatment of degenerative disorders of the CNS. ${ }^{2}{ }^{23}$ The aim is to introduce modified cells, such as fibroblasts taken from the patient, into the retina to act as a source of the missing protein. A retroviral vector is used to stably introduce the functional gene into the recipient cell genome under the control of a strong promoter. The expressed gene product can be modified so that it is secreted from the cell with the hope that it is then phagocytosed by target cells such as photoreceptors. Primary fibroblasts survive for extended periods of time within rodent (up to 18 months) and primate brains, although a decline in gene expression has been observed with time, suggesting the need for the concomitant expression of appropriate growth factors to maintain cell viability. ${ }^{23}$ This approach deserves to be explored because of the inherent difficulties of obtaining long term expression in cells such as photoreceptors using an in vivo approach. The most suitable site for transplanting the modified cells is unclear but the subretinal space, vitreous, and choroid are possibilities.

\section{Future developments}

It is difficult to predict the key ingredients required for success in retinal gene therapy. Less immunogenic vectors will certainly be helpful but one worrying possibility is that unless chromosomal integration of the introduced gene occurs, expression will be too short lived (for example, not more than 1 year) to be useful. None of the currently used vectors (AV, AAV, HSV1) integrates at an appreciable frequency, and although this can be seen as an advantage for dividing cells (less chance of oncogenic damage) it is probably a disadvantage in post-mitotic cells. This may necessitate the use of modified retroviral vectors which have low immunogenicity and now have the potential for integration into non-dividing neural cells. ${ }^{24}$

Good animal models are essential to evaluate the efficacy, safety, and potential for therapy in humans. Targeted disruption of specific genes and the creation of transgenic mutants are confined to rodents at present, but recent work suggests that this may change so that larger animal models become available. ${ }^{25}$ This will facilitate the evaluation process and shorten the step from animals to humans.

Adenoviral vectors are not efficient at transducing photoreceptors and it is possible that the success in delaying the progress of the $r d$ mouse retinal degeneration results from highly efficient RPE uptake and expression spilling over into adjacent photoreceptors. Bennett and coworkers noted that diffusion of lacZ protein was occurring from RPE to photoreceptors. ${ }^{14}$ The use of a photoreceptor specific promoter to drive expression should resolve this. Even if this is the case, fewer immunogenic AV vectors should lead to a longer duration of expression and improved photoreceptor rescue, if by an unexpected route. Similarly, if the apparently superior efficacy of AAV for transducing photoreceptors ${ }^{11-13}$ results from a combination of its small size and the presence of contaminating wild type $\mathrm{AV}^{18-19}$ or even $\mathrm{AAV}$, it is a rather oblique success. These and related studies provide valuable proofs of principle. However, the confusion relating to actual mechanisms brings to mind the plea for more basic research and the dangers of rushing into clinical trials before the efficacy of gene therapy techniques is adequately understood. This is nowhere more important than in the treatment of genetic eye disease, where the watchwords must remain animal models, systematic investigation and, above all, safety. The field clearly has promise but there will be no quick fixes. Research money is justified but it must go to those carrying out the hard groundwork.

I would like to thank Dr B Fleck, Dr B Dhillon, Professor D Porteous, and Dr K Dry for helpful discussions.

ALAN F WRIGHT

MRC Human Genetics Unit, Western General Hospital, Crewe Road, Edinburgh EH4 2XU 
1 Latchman D, ed. Genetic manipulation of the nervous system. London: Academic Press, 1996:1-276.

2 Blomer U, Naldini L Verma IM, Trono D, Gage FH. Applications of gene therapy to the CNS. Hum Mol Genet 1996;5:1397-404.

3 Johnson E. Gene therapy companies: launching against the tide. Gene Therapy 1996;3:841-2.

4 Friedmann T. Human gene therapy - an immature genie, but certainly out of the bottle. Nature Med 1996;2:144-7.

5 Marshall E. Less hype, more biology neded for gene therapy. Science 1995; 270:175.

6 Sullivan LS, Daiger SP. Inherited retinal degeneration: exceptional genetic and clinical heterogeneity. Mol Med Today 1996;2:380-6.

7 Faktorovich EG, Steinberg RH, Yasumura D, Matthes MT, LaVail MM. Photoreceptor degeneration in inherited retinal dystrophy delayed by basic fibroblast growth factor. Nature 1990;347:83-6.

8 Bennett J, Wilson J, Sun D, Forbes B, Maguire A. Adenovirus vector-mediated in vivo gene transfer into adult murine retina. Invest $O p h$ thalmol Vis Sci 1994;35:2535-42.

$9 \mathrm{Li} \mathrm{T}$, Adamian M, Roof DJ, Berson EL, Dryja TP, Roessler BJ, et al. In vivo transfer of a reporter gene to the retina mediated by an adenoviral vector. transfer of a reporter gene to the retina medi
Invest Ophthalmol Vis Sci 1994;35:2543-9.

10 Jomary C, Piper TA, Dickson G, Couture LA, Smith AE, Neal MJ, et al. Adenovirus-mediated gene transfer to murine retinal cells in vitro and in vivo. FEBS Lett 1994;347:117-22.

11 Jomary C, Vincent KA, Muzyczka N, Wadsworth SC, Smith AE, Neal $\mathrm{MJ}$, et al. Adenoassociated virus vector-mediated gene transfer to retinal cells in vitro and in vivo. Invest Ophthalmol Vis Sci 1995;36:S772 (Abstract 3569).

12 Hauswirth WW, Zolotukhin S, Muzyczka N, Flannery JG. Adeno-associated virus delivery of an opsin promoter driven reporter gene to the mouse and rabbit retina. Invest Ophthalmol Vis Sci 1995;36:S845 (Abstract 3884).

13 Ali RR, Reichel MB, Thrasher AJ, Levinsky RJ, Kinnon C, Kanuga N, et al. Gene transfer into the mouse retina mediated by an adeno-associated viral vector. Hum Molec Genet 1996;5:591-4.
14 Bennett J, Tanabe T, Sun D, Zeng Y, Kjeldbye, Gouras P, Maguire AM. Photoreceptor cell rescue in retinal degeneration $(r d)$ mice by in vivo gene therapy. Nature Med 1996;2:649-54.

15 Yang NS. Gene transfer into mammalian somatic cells in vivo. Crit Rev Biotechnol 1992;12:335-56.

16 McCarthy M. DNA vaccination: a direct line to the immune system. Lancet 1996;348:1232.

17 Grunzburg WH, Salmons B. Virus vector design in gene therapy. Mol Med Today 1995;1:411-7.

18 Fisher K, Guang-Ping G, Weitzman MD, DeMatteo R, Burda JF, Wilson JM. Transduction with recombinant adeno-associated virus for gene therapy is limited by leading-strand synthesis. F Virol 1996;70:520-32.

19 Ferrari F, Samulski T, Shenk T, Samulski RJ. Second-strand synthesis is a rate-limiting step for efficient transduction by recombinant adenoassociated virus vectors. F Virol 1996;70:3227-34.

20 Hart SL, harbottle RP, Cooper R, Miller A, Williamson R, Coutelle C. Gene delivery and expression mediated by an integrin-binding peptide. Gene Therapy 1995;2:552-4. (Corrigendum in 1996;3:1032-3.)

21 Hodgson CP, Solaiman R. Virosomes: cationic liposomes enhance retroviral transduction. Nature Biotec 1996;14:339-42.

22 Hangai M, Kaneda Y, Tanihara H, Honda Y. In vivo gene transfer into the retina mediated by a novel liposome system. Invest Ophthalmol Vis Sci 1996;37:2678-85.

23 Senut M-C, Suhr ST, Gage FH. Transplantation of genetically modified non-neuronal cells in the central nervous system. In: Latchman D, ed. non-neuronal cells in the central nervous system. In: Latchman D, ed. Genetic mani-202.

24 Naldini L, Blomer U, Gallay P, Ory D, Mulligan R, Gage FH, et al. In vivo gene delivery and stable transduction of nondividing cells by a lentiviral vector. Science 1996;272:263-7.

25 Campbell KHS, McWhir J, Ritchie WA, Wilmut I. Sheep cloned by nuclear transfer from a cultured cell line. Nature 1996;380:64-6.

\section{Corneal ulceration in the developing world - a silent epidemic}

Anyone who has spent time in Asia or Africa can invariably recall a vivid image of a blind beggar, sometimes an elderly person but frequently a child with opaque corneas, haunting the bazaars and marketplaces of cities and villages. The spectre is so common that it almost passes unnoticed, but these individuals who are bilaterally blind represent only a small fraction of the millions who suffer monocular blindness as a result of corneal trauma and subsequent microbial keratitis.

With the global figure of blindness rapidly approaching 40 million, attention naturally is focused on cataract, which is responsible for $50 \%$ or more of all visual disability, and trachoma which is still an enormous public health problem affecting 500 million people worldwide and responsible for $25 \%$ of all bilaterally blind individuals. ${ }^{1}$ Xerophthalmia, onchocerciasis, and glaucoma account for several millions more of the $85 \%$ of the world's blind individuals who live in developing countries in Asia and Africa. ${ }^{2}$

While corneal blindness in the developing world has traditionally been attributed to trachoma, xerophthalmia, measles, neonatal ophthalmia, and leprosy, Thylefors ${ }^{3}$ contends that the importance of superficial corneal trauma in agricultural work, which frequently leads to rapidly progressing corneal ulceration and visual loss, has been overlooked as a worldwide cause of monocular blindness. He estimates that up to $5 \%$ of all blinding conditions are directly related to ocular trauma and subsequent infection. Population based studies in several countries tend to support this assumption. In the Nepal blindness survey corneal trauma and ulceration were found to be the second leading cause of unilateral visual loss after cataract, accounting for $7.9 \%$ of all blind eyes. ${ }^{4}$ In Malawi, ${ }^{5}$ Tanzania,${ }^{6}$ and Bangladesh, ${ }^{7}$ corneal scarring was found to be responsible for $39-55 \%$ of all cases of unilateral blindness. Surveys of blind children in Africa have shown that approximately $70 \%$ of all visual disability in this group is caused by corneal opacification. ${ }^{8}$
Even though the prevalence of corneal scarring in a population may be used as an indication of the occurrence of corneal ulceration, the true incidence of keratitis can only be determined by a large population based survey. In the USA Erie et $a l^{9}$ reported the incidence of ulcerative keratitis in a carefully defined population in Olmsted County, Minnesota over a 39 year period from 1950 to 1988. In this retrospective population based survey the mean age and sex adjusted incidence of ulcerative keratitis was 5.3 per 100000 population increasing to 11.0 per 100000 during the $1980 \mathrm{~s}$, the increase corresponding to the widespread use of cosmetic contact lenses. Until recently, a similar population based study in a developing country had not been documented. In 1996 Gonzales et $a l^{10}$ reported the incidence of corneal ulceration in Madurai District, Tamilnadu, south India. This retrospective population based study surveyed all of the corneal ulcers occurring in 1993 in Madurai District, an administrative area in the state of Tamilnadu with a population of over three and a half million. There were 1148 cases of corneal ulceration recorded in medical records in the district, yielding an annual incidence of 3.4 cases of corneal ulceration per 10000 population. But, by carefully questioning all of the medical practitioners in the district and examining hospital records and patient charts in ophthalmologists' offices, Gonzales et al were able to extrapolate a much truer estimated annual incidence of corneal ulceration of 11.3 per 10000 population.

To put these figures in perspective, the incidence of corneal ulceration in Olmsted County, Minnesota from 1980 to 1988 was 11.0 per 100000 population. The estimated true incidence of corneal ulceration in Madurai District, Tamilnadu, south India in 1993 was 113.0 per 100000 population, or 10 times the incidence reported in the USA. Applying the 1980-8 incidence rate in Olmsted County to the 1990 US population yields an estimate of 27000 corneal ulcers annually. Applying the 1993 incidence rate in 